\title{
A meta-analysis of minimally invasive surgery versus thoracotomy for centrally located non-small cell lung cancer
}

\author{
Zhengjun Li ${ }^{1}$, Mozhu Xia ${ }^{2}$, Chang Liu ${ }^{1}$, Tao Wang ${ }^{3}$, Yi Ren ${ }^{1}$, Yongyu Liu ${ }^{1}$ \\ ${ }^{1}$ Department of Thoracic Surgery, Shenyang Chest Hospital, Shenyang, China; ${ }^{2}$ Department of Operation Room, First Affiliated Hospital, China \\ Medical University, Shenyang, China; ${ }^{3}$ Department of Anesthesia, Shenyang Chest Hospital, Shenyang, China \\ Contributions: (I) Conception and design: Y Liu, Y Ren; (II) Administrative support: Y Liu, Y Ren; (III) Provision of study materials or patients: Z Li, \\ M Xia, C Liu; (IV) Collection and assembly of data: Z Li, M Xia, T Wang, C Liu; (V) Data analysis and interpretation: Z Li, T Wang, Y Ren; (VI) \\ Manuscript writing: All authors; (VII) Final approval of manuscript: All authors. \\ Correspondence to: Yi Ren; Yongyu Liu. Department of Thoracic Surgery, Shenyang Chest Hospital, Shenyang, China. \\ Email: 498857876@qq.com; freeman-2006@163.com.
}

Background: Surgery is established as the most effective treatment for central lung cancer. Minimally invasive surgery (MIS) is gaining popularity. The decision of whether surgical treatment of central lung cancer should be minimally invasive or a conventional thoracotomy is a critical decision for the thoracic surgeon. However, whether MIS is more advantageous than other surgical treatments for central lung cancer. This study aimed to compare the short- and long-term results of MIS and conventional thoracotomy in patients with central lung cancer.

Methods: This meta-analysis was conducted using the PubMed, Embase, Wiley Online Library, Google Scholar, Wanfang, and China National Knowledge Infrastructure databases. Searches for relevant studies were conducted in strict accordance with research protocols detailed in the Cochrane handbook. The primary endpoints for comparison between the two surgical methods were perioperative and long-term survival. A 95\% confidence interval (CI) for relative risk (RR)/mean difference (MD) was calculated to assess the strength of the correlation.

Results: Nine studies that met the inclusion and exclusion criteria were eventually included in this meta-analysis. These studies involved a total of 5,869 patients [MIS, $n=1,140$ versus thoracotomy (TH), $\mathrm{n}=4,729$ ]. The 3 - and 5-year disease-free survival (DFS) and the 2-, 3-, and 5-year overall survival (OS) were similar for the MIS and TH groups [OR: 0.86 (95\% CI: 0.51-1.43); P=0.55; OR: 1.01 (95\% CI: 0.43-2.36); P=0.99, OR: 0.91 (95\% CI: 0.78-1.05); P=0.18; OR: 0.90 (95\% CI: 0.77-1.06); P=0.22; OR: 0.95 (95\% CI: $0.25-1.53) ; \mathrm{P}=0.30]$. A subgroup analysis of 8 articles revealed no statistical difference in the pathological type of non-small cell lung cancer (squamous cell carcinoma or adenocarcinoma) between the two groups [OR: 0.99 (95\% CI: 0.89-1.09); $\mathrm{P}=0.81$ ]. However, the MIS group had a lower incidence of blood loss, duration of hospital stay, and fewer complications [MD: -46.25 (95\% CI: -85.05 to -7.46 ); $\mathrm{P}=0.02$; MD: -1.93 (95\% CI: -3.15 to -0.7 ); $\mathrm{P}=0.002$; MD: 0.73 (95\% CI: 0.61-0.88); P=0.001].

Conclusions: MIS was shown to be a more effective option to conventional thoracotomy for the treatment of central lung cancer.

Keywords: Central lung cancer; minimally invasive surgery (MIS); meta-analysis

Submitted Sep 17, 2020. Accepted for publication Dec 26, 2020.

doi: $10.21037 /$ jtd-20-3273

View this article at: http://dx.doi.org/10.21037/jtd-20-3273 


\section{Introduction}

Lung cancer has the highest morbidity and mortality of any malignant tumor worldwide. Since the 1990s, the minimally invasive surgical (MIS) techniques of video-assisted thoracic surgery (VATS) and roboticassisted thoracic surgery (RATS) have been applied in the diagnosis and treatment of intrathoracic diseases.

Compared with conventional thoracotomy, thoracoscopic surgery has many advantages, including less trauma and pain, faster recovery, fewer complications, and a shorter hospitalization period, and it is also associated with a higher tolerance to postoperative adjuvant therapy (1-3). Central lung cancer, which is in close proximity to the hilum of the lung and originates from the proximal subsegmental bronchi, often requires sleeve lobectomy or unilateral pneumonectomy, due to the specificity of its anatomical site and pathological type.

The advantages MIS over thoracotomy (TH) for central lung cancer are unknown. To demonstrate that MIS has the same application value in locally advanced central lung cancer as it has in early peripheral lung cancer, clinical studies are needed to determine the following: (I) the feasibility and safety of using MIS techniques to perform pneumonectomy and sleeve removal; (II) the feasibility of MIS as a method for improving perioperative efficacy and patient benefit compared with traditional surgery; (III) the efficacy of MIS compared to open surgery in oncology, given lung cancer patients comprise the target treatment population. Therefore, this metaanalysis was designed to be the first to compare the postsurgical short- and long-term outcomes of patients with centrally located non-small cell lung cancer treated with MIS or TH. The results of our study will aid future surgical decision-making and the design of effective and safe treatment strategies for centrally located non-small cell lung cancer.

We present the following article in accordance with the PRISMA reporting checklist (available at http://dx.doi. org/10.21037/jtd-20-3273).

\section{Methods}

\section{Data sources and search strategy}

Systematic searches of the PubMed, Embase, Google Scholar, Wiley Online Library, Wanfang, and China National Knowledge Infrastructure databases were performed using the terms "minimally invasive surgery", "video-assisted thoracic surgery", "centrally located lung cancer", "non-small cell lung cancer", and "thoracotomy" combined with Boolean operators AND or OR (from the date of inception until June 2020). The reference lists of articles retrieved in the initial search were checked for additional suitable studies, which were subsequently included (Figure 1).

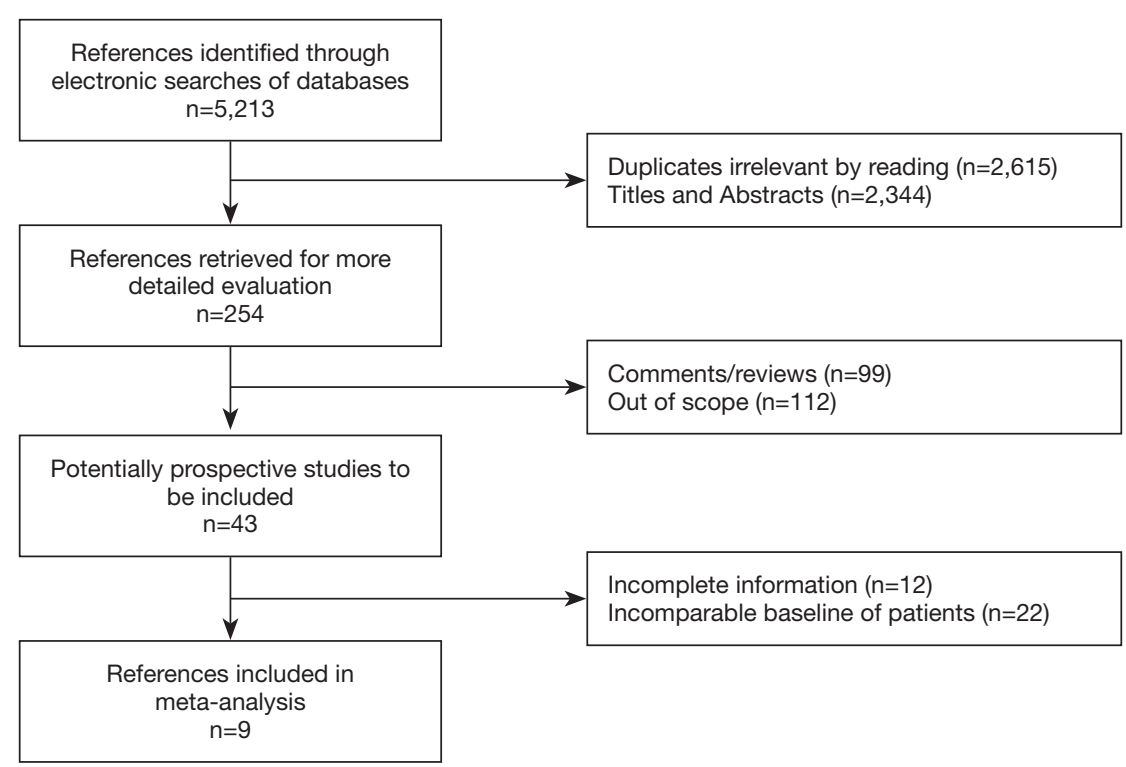

Figure 1 Flowchart of the study selection process. 


\section{Selection of studies}

The articles included in the present meta-analysis were required to meet the following inclusion/exclusion criteria: (I) randomized controlled trials or non-randomized comparison trials with parallel controls that (II) compared MIS and thoracotomy, and (III) included sufficient data for calculating relative risk (RR)/odds ratio (OR)/mean difference (MD) and 95\% confidence interval (CI). Where the same population had been used in multiple studies, only the most up-todate research was included. Studies that exhibited a noncontrolled design, case reports, or trials with incomplete study data were excluded.

\section{Data extraction}

Data were independently extracted by three investigators ( $\mathrm{Z} \mathrm{Li}, \mathrm{M} \mathrm{Xia}$, and C Liu). The data extracted from each study included, but were not limited to, the first author, country, publication year, number of cases, and outcomes. Doubled data were included. The Cochrane Collaboration's tool for assessing risk of bias was applied to each selected study, covering the following domains: (I) random sequence generation; (II) allocation concealment; (III) blinding of participants and personnel; (IV) blinding of outcome assessment; (V) incomplete outcome data; (VI) selective reporting; and (VII) other bias. These domains were judged as "yes", "no", or "unclear".

\section{Definition of MIS}

MIS: this included single-hole, two-hole, and three-hole thoracoscopic operations, and robot-assisted MIS without the use of rib retractor.

\section{Statistical analysis}

All extracted data were entered into Review Manager 5.3 software by two investigators ( $\mathrm{Z} \mathrm{Li}$ and $\mathrm{M} \mathrm{Xia)}$, working in parallel. The $95 \%$ confidence intervals of odds ratios (OR) or mean differences (MD) were used to calculate dichotomous and continuous values, respectively. Heterogeneity was evaluated using the $\chi^{2}$ and $\mathrm{I}^{2}$ tests; $\mathrm{I}^{2}<25 \%$ and $\mathrm{I}^{2}>50 \%$ reflected small and large inconsistencies, respectively. $\mathrm{P}>0.10$ indicated homogeneity between studies, in which case a fixed-effects model was used. $\mathrm{P}<0.10$ and $\mathrm{I}^{2}<50 \%$ indicated acceptable heterogeneity between studies, and a fixed-effects model was also adopted. $\mathrm{P}<0.10$ and $\mathrm{I}^{2}>50 \%$ indicated unacceptable heterogeneity; under these circumstances, a random-effects model was adopted. $\mathrm{P}<0.05$ was considered statistically significant. Heterogeneity was estimated using forest plots and publication bias was estimated using funnel plots; the funnel plot model was also used to detect deviations. The risk of bias was assessed using the asymmetric test sizes of treatment outcomes in funnel plots.

\section{Results}

\section{Study characteristics}

Nine studies involving a total of 5,869 patients (1,140 and 4,729 patients who underwent MIS and TH, respectively) were finally included in this meta-analysis. Figure 1 presents the flowchart of the literature search, which was performed in accordance with the PRISMA statement. Patient clinical data from each study are presented in Table 1.

\section{Surgery time}

Eight studies compared the surgery times of MIS and TH. The duration of surgery with the TH method was shown to be reduced compared to that with the MIS method [MD: 26.61 (95\% CI: 5.13-48.1); $\mathrm{P}=0.02$ ]. For this analysis, significant statistical heterogeneity was found $\left(\mathrm{I}^{2}=92 \%\right.$, $\left.\chi^{2}=86.37, \mathrm{df}=7 ; \mathrm{P}<0.00001\right)$.

\section{Blood loss}

Eight studies compared the amount of blood loss between MIS and TH. The MIS method was shown to result in less blood loss compared with the TH method [MD: -46.25 (95\% CI: -85.05 to -7.46 ); $\mathrm{P}=0.02$ ]. For this analysis, no statistical heterogeneity was found $\left(\mathrm{I}^{2}=81 \%, \chi^{2}=36.4\right.$, df $=7$; $\mathrm{P}<0.00001$ ) (Figure 2).

\section{Tube duration}

Eight studies compared postoperative tube duration between MIS and TH. The two methods displayed a statistically similar incidence of tube duration length [MD: -0.53 (95\% CI: -1.17 to 0.11 ); $\mathrm{P}=0.10]$. For this analysis, significant statistical heterogeneity was found $\left(\mathrm{I}^{2}=71 \%\right.$, $\left.\chi^{2}=24.39, \mathrm{df}=7 ; \mathrm{P}=0.001\right)$. 
Table 1 Characteristics of the included trials

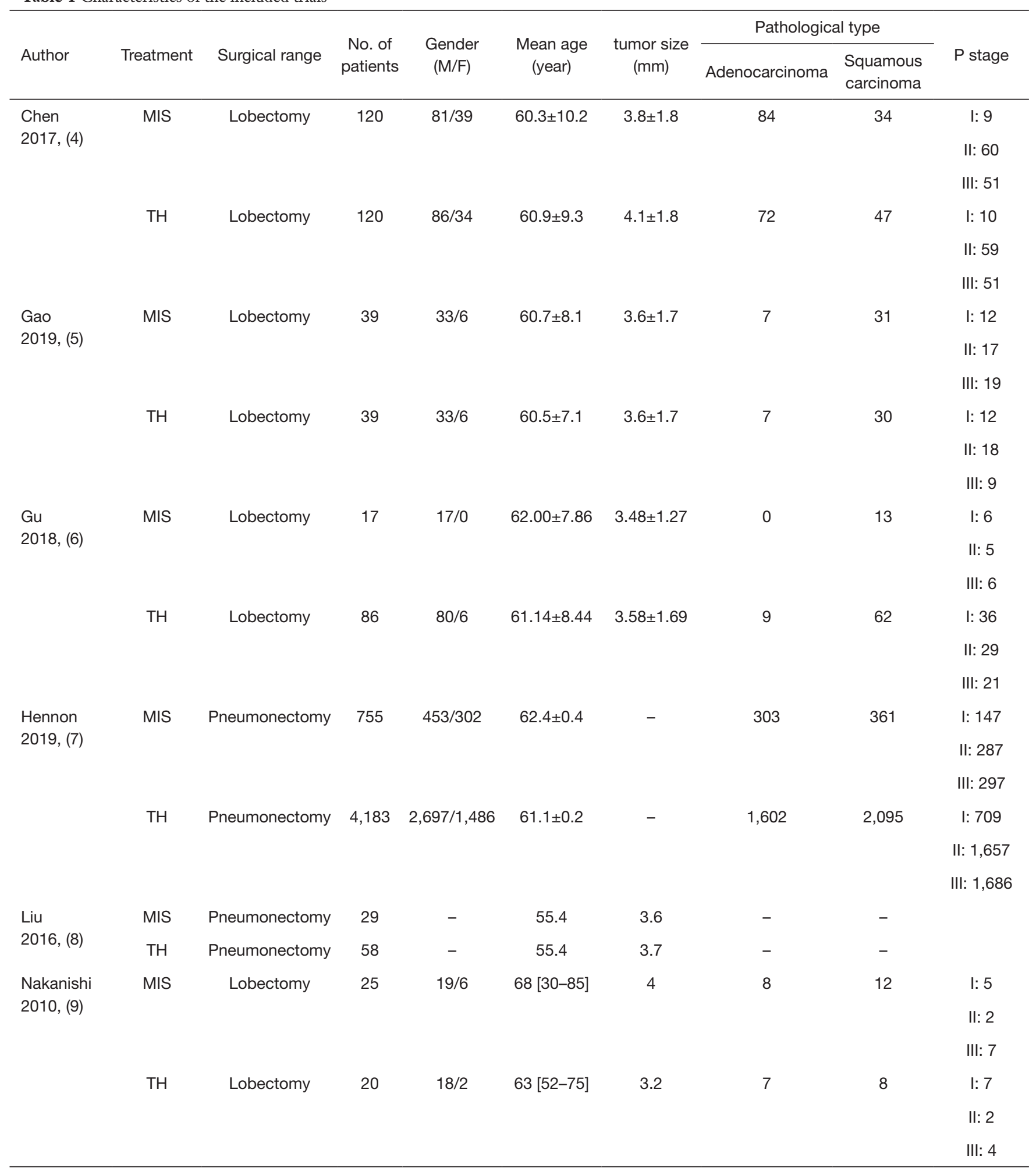

Table 1 (continued) 
Table 1 (continued)

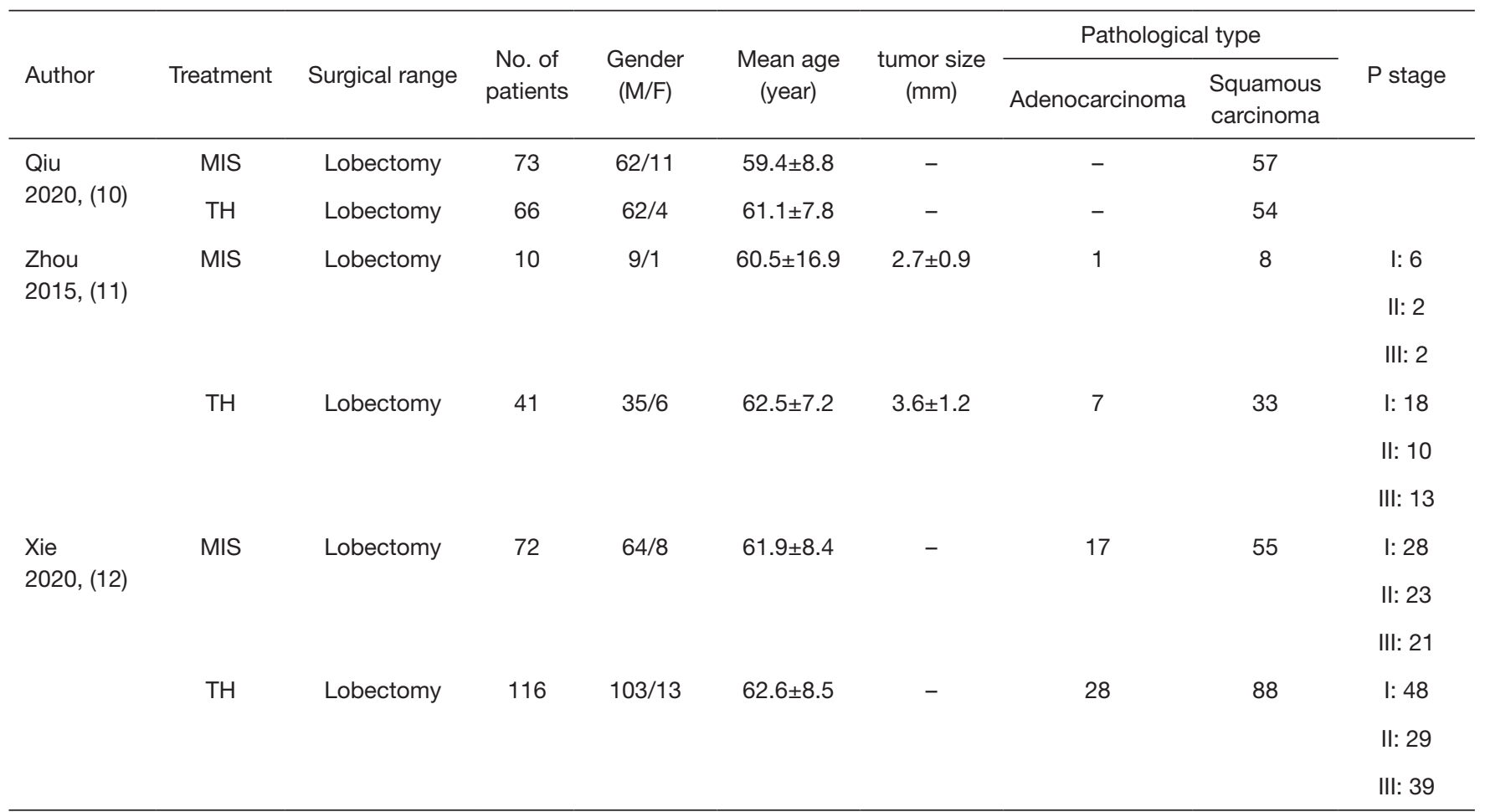

MIS, minimally invasive surgery; $\mathrm{TH}$, traditional surgery.

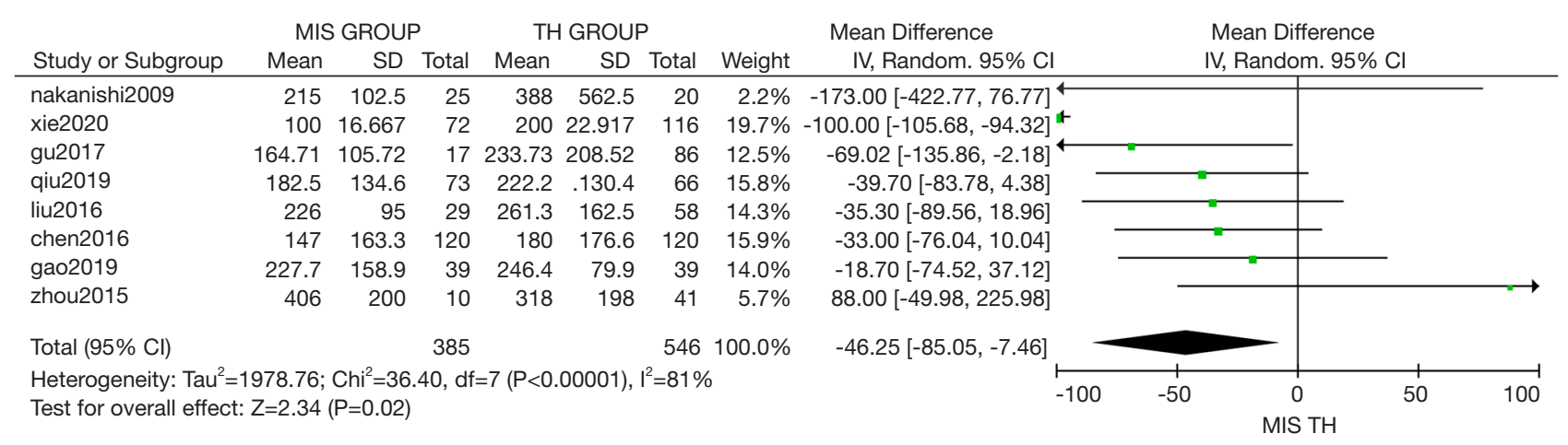

Figure 2 The MIS group showed less blood loss than the TH group. MIS, minimally invasive surgery; TH, traditional surgery.

\section{Length of hospital stay}

Eight studies compared the length of hospital stay (LOS) between MIS and TH. The MIS group was found to have a shorter LOS than the TH group [MD: -1.93 (95\% CI: -3.15 to -0.7$) ; \mathrm{P}=0.002]$. For this analysis, significant statistical heterogeneity was found $\left(\mathrm{I}^{2}=85 \%, \chi^{2}=48.1, \mathrm{df}=7\right.$; $\mathrm{P}<0.00001$ ) (Figure 3).

\section{Complications}

Seven studies compared the incidence of postoperative complications between MIS and TH. Patients who underwent MIS experienced fewer post-surgical complications than patients who underwent TH [MD: 0.73 (95\% CI: 0.61-0.88); $\mathrm{P}=0.001]$. For this analysis, mild heterogeneity was found $\left(\mathrm{I}^{2}=42 \%, \chi^{2}=10.3, \mathrm{df}=6 ; \mathrm{P}=0.11\right)$. 


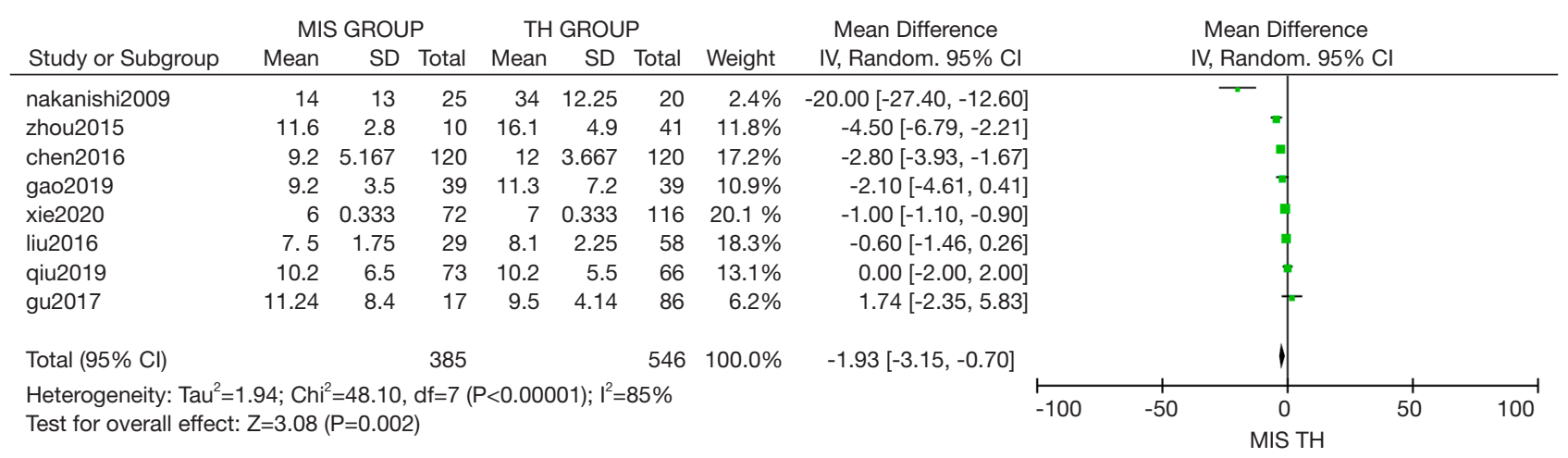

Figure 3 The MIS group showed shorter length of hospital stay compared with the TH group. MIS, minimally invasive surgery; TH, traditional surgery.

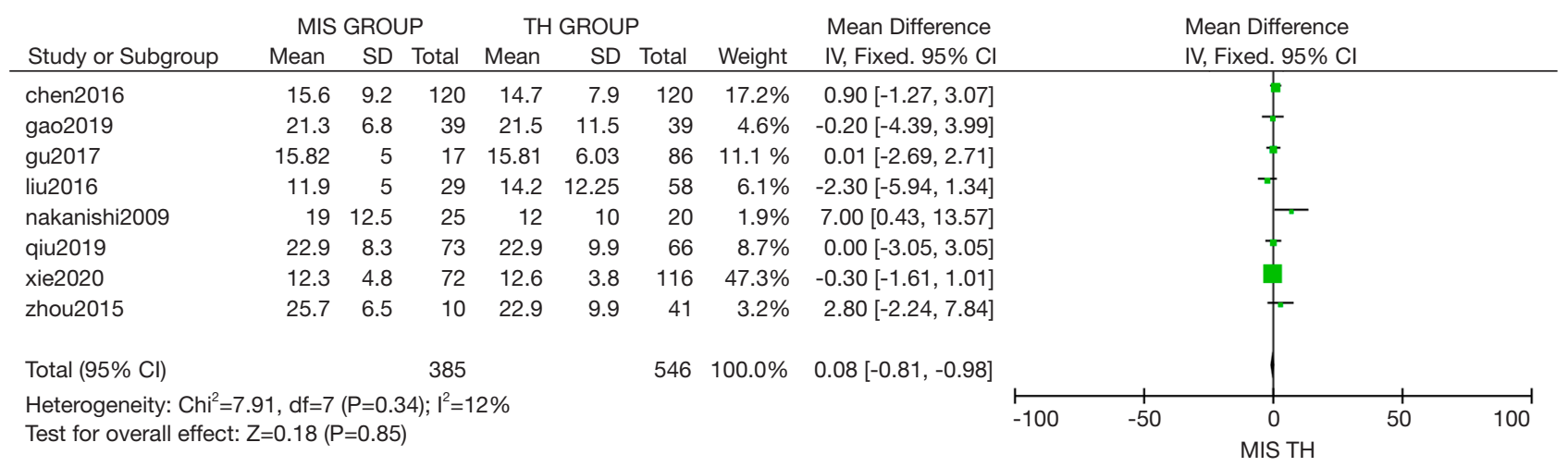

Figure 4 No statistical difference was observed in the number of total lymph nodes removed between the two groups.

\section{Total number of lymph node stations and total number of lymph nodes dissected}

Seven studies compared the total number of lymph node stations dissected between MIS and TH. There was no statistically significant difference between the two methods [MD: -0.03 (95\% CI: -0.24 to 0.17 ); $\mathrm{P}=0.75$ ]. For this analysis, no statistical heterogeneity was found $\left(\mathrm{I}^{2}=0 \%\right.$, $\left.\chi^{2}=3.03, \mathrm{df}=5 ; \mathrm{P}=0.7\right)$.

Eight studies compared the total number of lymph nodes dissected between MIS and TH. The two methods showed a statistically similar number of total lymph nodes [MD: 0.08 (95\% CI: -0.81 to 0.98 ); $\mathrm{P}=0.85$ ]. For this analysis, mild heterogeneity was found $\left(\mathrm{I}^{2}=12 \%, \chi^{2}=7.91, \mathrm{df}=7 ; \mathrm{P}=0.34\right)$ (Figure 4).

\section{Overall recurrence}

Three studies compared the rate of postoperative disease recurrence between MIS and TH. Statistically similar rates of overall, local-regional, and distant recurrence were observed for the two methods [OR: 0.79 (95\% CI: 0.54-1.16); $\mathrm{P}=0.23$; OR: 1.04 (95\% CI: 0.65-1.65); P=0.87; OR: 0.64 (95\% CI: $0.40-1.05) ; \mathrm{P}=0.08]$. For this analysis, mild heterogeneity was found $\left(\mathrm{I}^{2}=15 \%, \chi^{2}=2.35, \mathrm{df}=2 ; \mathrm{P}=0.31 ; \mathrm{I}^{2}=44 \%, \chi^{2}=3.54\right.$, $\mathrm{df}=2 ; \mathrm{P}=0.17)$ in overall and local-regional recurrence research, and no statistical heterogeneity was found $\left(\mathrm{I}^{2}=0 \%\right.$, $\left.\chi^{2}=1.25, \mathrm{df}=2 ; \mathrm{P}=0.54\right)$ in distant recurrence research.

\section{Disease-free survival (DFS)}

Five studies compared 3-year DFS and 3 studies compared 5-year DFS between MIS and TH. Statistically similar 3and 5 -year DFS rates were observed for the two methods [OR: 0.86 (95\% CI: 0.51-1.43); P=0.55; OR: 1.01 (95\% CI: $0.43-2.36) ; \mathrm{P}=0.99]$. For this analysis, significant statistical heterogeneity was found $\left(\mathrm{I}^{2}=57 \%, \chi^{2}=9.21, \mathrm{df}=4 ; \mathrm{P}=0.06\right)$ in 3 -year DFS research and $\left(\mathrm{I}^{2}=72 \%, \chi^{2}=7.14, \mathrm{df}=2 ; \mathrm{P}=0.03\right)$ 


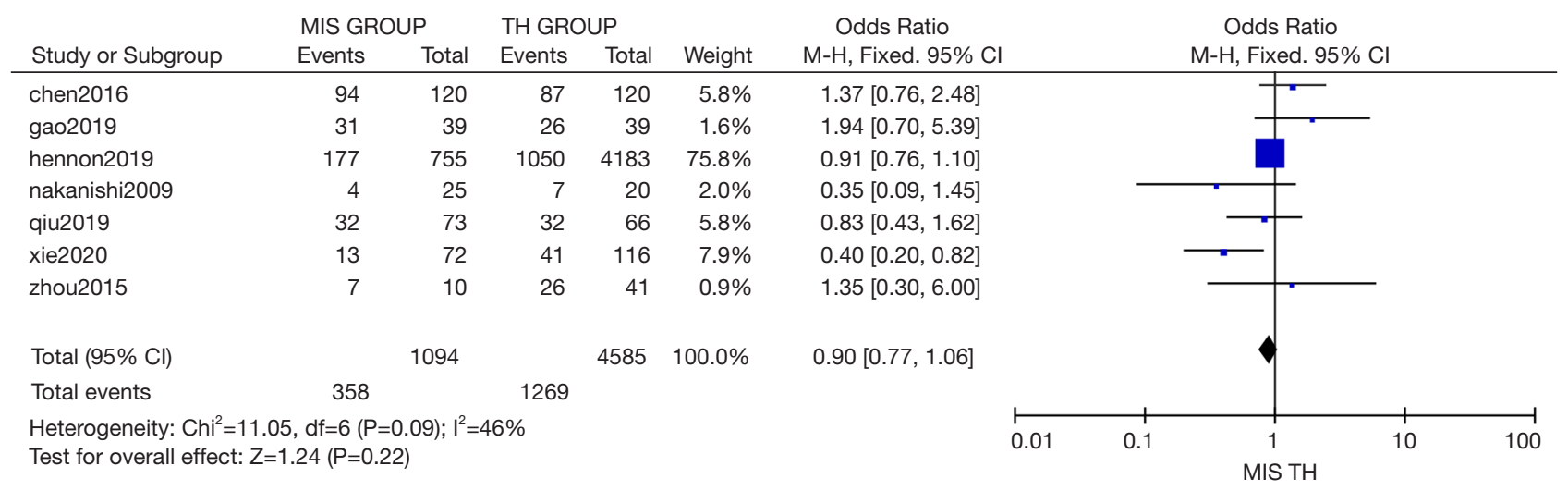

Figure 5 No statistically significant difference was observed in 3-year overall survival between the two groups.

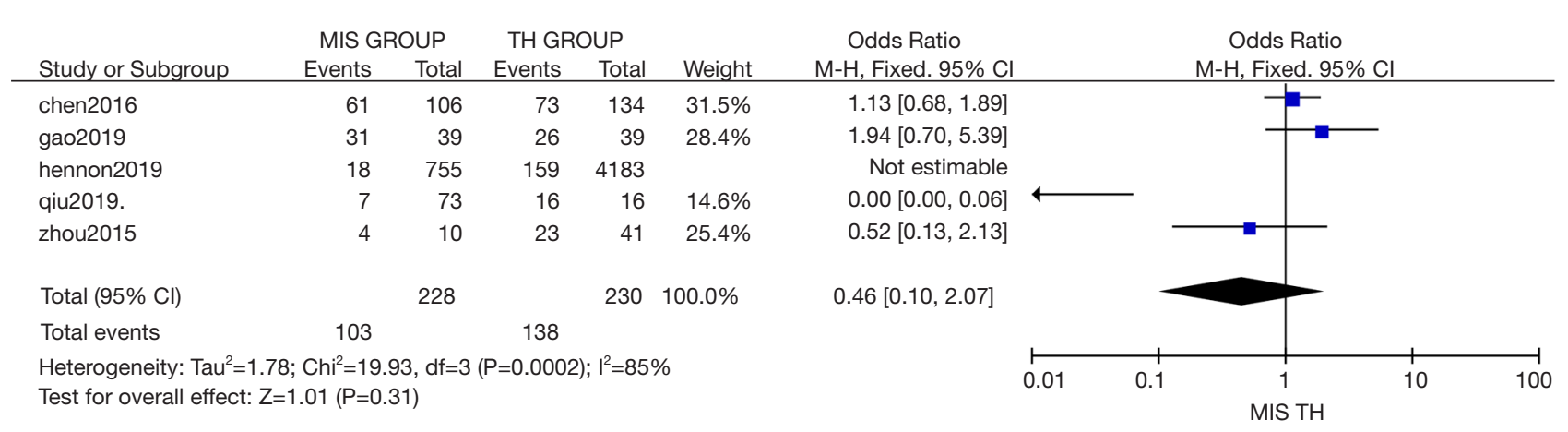

Figure 6 No statistically significant difference was observed in 5 -year overall survival between the two groups.

in 5-year DFS research.

\section{Overall survival (OS)}

Six studies compared 2-year OS, 7 studies compared 3-year OS, and 4 studies compared 5 -year OS between MIS and TH. Statistically similar 2-, 3-, and 5-year OS rates were observed between the two methods [OR: 0.91 (95\% CI: 0.78-1.05); $\mathrm{P}=0.18$; OR: 0.90 (95\% CI: 0.77-1.06); $\mathrm{P}=0.22$ (Figure 5); OR: 0.46 (95\% CI: 0.10-2.07); $\mathrm{P}=0.31$ (Figure 6)]. For this analysis, mild heterogeneity was found $\left(\mathrm{I}^{2}=21 \%\right.$, $\left.\chi^{2}=6.32, \mathrm{df}=5 ; \mathrm{P}=0.28 ; \mathrm{I}^{2}=46 \%, \chi^{2}=11.05, \mathrm{df}=6 ; \mathrm{P}=0.09\right)$ in 2-year OS and 3 -year OS research and significant statistical heterogeneity was found $\left(\mathrm{I}^{2}=81 \%, \chi^{2}=20.97, \mathrm{df}=4\right.$; $\mathrm{P}=0.0003)$ in 5-year OS research.

\section{Subgroup analysis}

Squamous cell carcinoma and adenocarcinoma

A subgroup analysis of the pathological types was performed for both surgical methods. The results showed no statistical difference in the pathologic type of non-small cell lung cancer (squamous cell carcinoma or adenocarcinoma) between MIS and TH [OR: 0.99 (95\% CI: 0.89-1.09); $\mathrm{P}=0.81$ ].

\section{Lobectomy and pneumonectomy}

Surgical procedures for central lung cancer in both groups included lobectomy and pneumonectomy. The results were similar to the overall results, including blood loss, LOS, lymph node status, and complications. There were no statistically significant differences in these indicators between the two types of surgery and the overall comparison.

No difference in 5-year OS was noted between the minimally invasive and open lobectomy groups. Additionally, no difference was observed in 5 -year OS between the two methods of pneumonectomy.

\section{Discussion}

The surgical treatment of central lung cancer is highly 
complex and consistently challenging for thoracic surgeons. The development of surgical techniques and the progress of MIS has led to an increase in its application in the treatment of patients with central lung cancer. Until the early 21 st century, sleeve lobectomy was considered a contraindication for minimally invasive thoracoscopic surgery.

The aim of our analysis was to identify the benefits of MIS, in order to eliminate the surgeon's bias in the selection of minimally invasive or TH surgery. The majority of our selected articles reported propensity score matching. The standard surgical methods for central lung cancer include complex lobectomy or pneumonectomy. Li et al. showed that complex lobectomy for central lung cancer is more beneficial for patients than pneumonectomy (13). In this study, MIS included minimally invasive methods of non-thoracotomy, including single-hole, double-hole, standard, and robotic thoracoscopic surgery, and did not include converted thoracotomy. In the perioperative period, the operative time and intraoperative blood loss are important indexes for assessing the feasibility of the surgical method. Similar to our findings, Zhou et al. showed that the difference in operative time between the minimally invasive and open group was statistically significant $(226 \pm 37$ vs. $166 \pm 40 \mathrm{~min}$ ) (11). In this meta-analysis, the TH method showed reduced surgery duration compared with the MIS method [MD: 26.61 (95\% CI: 5.13-48.1); $\mathrm{P}=0.02]$. Patients in the minimally invasive group displayed less bleeding and shorter durations of postoperative hospital stay, compared to the open group, thereby improving their prognosis and reducing the cost of treatment.

Complication types were similar in both groups, but the incidence of complications in the minimally invasive group was significantly lower than that in the TH group [MD: 0.73 (95\% CI: 0.61-0.88); $\mathrm{P}=0.001]$. Anastomotic complications, such as bronchopleural fibril fistula and anastomotic stenosis, are the major concerns in sleeve lobectomy. One of the advantages of MIS is the low incidence of postoperative complications, and minimally invasive thoracoscopic sleeve lobectomy is superior to thoracotomy in relation to this. Our study demonstrated a reduced rate of complications after MIS, compared with after the TH method [MD: 0.76 (95\% CI: 0.63-0.91); $\mathrm{P}=0.004]$. The incidence of anastomotic complications after thoracotomy has been reported to range from $2.0-6.9 \%$ (14-18), while the incidence of minimally invasive sleeve-lobotomy has been reported as $0-15.4 \%$ in studies with limited, small samples $(11,19)$.

No differences were observed in performance, status, or comorbidities, irrespective of whether adjuvant chemotherapy was administered. According to Lee et al. (20), the VATS group displayed superior adherence to adjuvant chemotherapy without a dose reduction. However, this difference was not observed to be significant. In two recent studies, long-term survival and the patterns of recurrence were similar in both groups $(21,22)$. There was no significant difference between the two groups in terms of locoregional or distant recurrence. These results may explain some of the misconceptions and confusion associated with minimally invasive techniques among surgeons. The data also indirectly confirmed that minimally invasive techniques for central lung cancer, including complex lobectomy and pneumonectomy, could not create technical barriers.

Okada and colleagues (23) established lymphatic metastasis as the critical factor affecting the long-term survival of central lung cancer patients treated with sleeve lobectomy. Questions pertaining to the adequacy of MIS lymph node dissection have been raised before. Traditionally, lymph node dissection by MIS has not been considered sufficient; specifically, due to the limited surgical field and angle of the surgical instrument, it is considered to provide incomplete lymph node dissection in terms of station number or total number of nodes. Our results demonstrated no differences in the number of lymph nodes dissected or the number of lymph node stations between the TH and MIS groups. More and more data have confirmed that, with the progress of surgery, MIS can achieve the same effect as open surgery in terms of lymph node dissection. Our findings were consistent with previous data obtained from the American College of Surgeons Oncology Group Z0030 trial, which showed no significant difference in the number of lymph nodes dissected in the MIS group compared with that in the standard lobotomy group (24).

In our study, no statistical significance was noted in OS or DFS between the groups. Subgroup analyses also showed no statistically significant difference in the pathological type of non-small cell lung cancer (squamous cell carcinoma or adenocarcinoma) between the two surgical methods. No difference was noted in the 3 -year survival rate between minimally invasive and open lobectomy. Additionally, no difference was observed in the 3 -year survival rate between minimally invasive and open pneumonectomy. The data demonstrated that MIS could procure a radical resection without compromising the oncological outcome. 


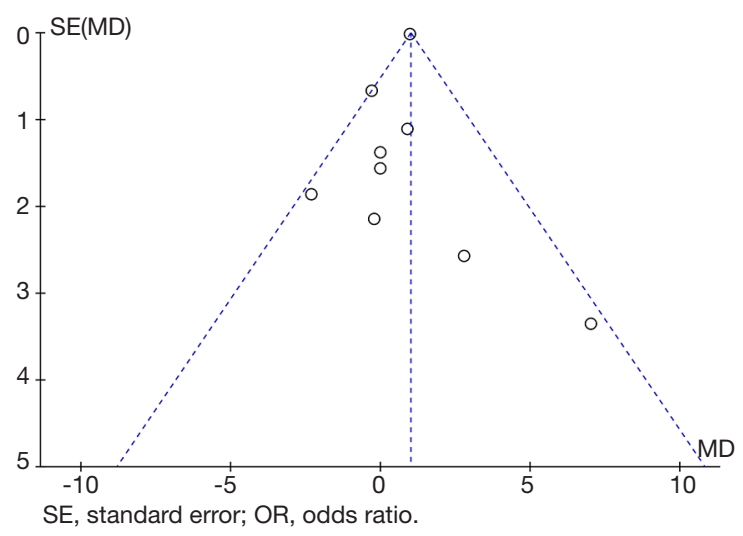

Figure 7 Funnel plot of total lymph nodes.

\section{Limitations of the study}

Our conclusions may be limited by several factors. First, not all data originated from randomized controlled trials. Consequently, the overall level of clinical evidence was relatively low. Publication bias existed in the included studies. Surgeons without the experience or skills necessary to perform open surgery may be less willing to publish their data if they are accepted for publication. In addition, there are many subtle differences in the technical levels of surgeons with different professional titles, regardless of the country. All of these factors can cause publication bias. Finally, the asymmetry shown in the funnel plot might be attributable to various factors, including publication bias (Figure 7).

\section{Conclusions}

In summary, MIS for centrally located lung cancer is a safe and effective option, with oncological outcomes similar to those obtained with open procedures. Moreover, both lobectomy and pneumonectomy achieved long-term survival similar to that achieved by traditional surgery.

\section{Acknowledgments}

The authors gratefully acknowledge the contribution of Zhengjun Li and Tao Wang in data extraction and software input.

Funding: This study was supported by the Liaoning Province Science and Technology Public Welfare Research Fund Project (\#GY-20170016) and the Establishment of Early Diagnosis and Early Treatment Model for Lung
Cancer and Research Project of Early Lung Cancer Driver Genes in Liaoning Province (2019JH8/10300089).

\section{Footnote}

Reporting Checklist: The authors have completed the PRISMA reporting checklist. Available at http://dx.doi. org/10.21037/jtd-20-3273

Conflicts of Interest: All authors have completed the ICMJE uniform disclosure form (available at http://dx.doi. org/10.21037/jtd-20-3273). The authors have no conflicts of interest to declare.

Ethical Statement: The authors are accountable for all aspects of the work in ensuring that questions related to the accuracy or integrity of any part of the work are appropriately investigated and resolved.

Open Access Statement: This is an Open Access article distributed in accordance with the Creative Commons Attribution-NonCommercial-NoDerivs 4.0 International License (CC BY-NC-ND 4.0), which permits the noncommercial replication and distribution of the article with the strict proviso that no changes or edits are made and the original work is properly cited (including links to both the formal publication through the relevant DOI and the license). See: https://creativecommons.org/licenses/by-nc-nd/4.0/.

\section{References}

1. Swanson SJ, Herndon JE, D'Amico TA, et al. Videoassisted thoracic surgery lobectomy: report of CALGB 39802-a prospective, multi-institution feasibility study. J Clin Oncol 2007;25:4993-7.

2. Cao C, Manganas C, Ang SC, et al. Video-assisted thoracic surgery versus open thoracotomy for non-small cell lung cancer: a meta-analysis of propensity score-matched patients. Interact Cardiovasc Thorac Surg 2013;16:244-9.

3. Guerrera F, Olland A, Ruffini E, et al. VATS lobectomy vs. open lobectomy for early-stage lung cancer: an endless question-are we close to a definite answer? J Thorac Dis 2019;11:5616-8.

4. Chen K, Wang X, Yang F, et al. Propensity-matched comparison of video-assisted thoracoscopic with thoracotomy lobectomy for locally advanced non-small cell lung cancer. J Thorac Cardiovasc Surg 2017;153:967976.e2. 
5. Gao HJ, Jiang ZH, Gong L, et al. Video-assisted vs thoracotomy sleeve lobectomy for lung cancer: a propensity matched analysis. Ann Thorac Surg 2019;108:1072-9.

6. Gu C, Pan X, Chen Y, et al. Short-term and mid-term survival in bronchial sleeve resection by robotic system versus thoracotomy for centrally located lung cancer. Eur J Cardiothorac Surg 2018,53,648-55.

7. Hennon MW, Kumar A, Devisetty H, et al. Minimally Invasive Approaches Do Not Compromise Outcomes for Pneumonectomy: A Comparison Using the National Cancer Database. J Thorac Oncol 2019;14:107-14.

8. Liu Y, Gao Y, Zhang H, et al. Video-assisted versus conventional thoracotomy pneumonectomy. J Thorac Dis 2016;8:3537-42.

9. Nakanishi R, Fujino Y, Oka S, et al. Video-assisted thoracic surgery involving major pulmonary resection for central tumors. Surg Endosc 2010;24:161-9.

10. Qiu T, Zhao Y, Xuan Y, et al. Robotic sleeve lobectomy for centrally located non-small cell lung cancer: a propensity score weighted comparison with thoracoscopic and open surgery. J Thorac Cardiovasc Surg 2020;160:838-846.e2.

11. Zhou S, Pei G, Han Y, et al. Sleeve lobectomy by videoassisted thoracic surgery versus thoracotomy for non-small cell lung cancer. J Cardiothorac Surg 2015;10:116.

12. Xie D, Deng J, Gonzalez-Rivas D, et al. Comparison of video-assisted thoracoscopic surgery with thoracotomy in bronchial sleeve lobectomy for centrally located non-small cell lung cancer. J Thorac Cardiovasc Surg 2021;161:40313.e2.

13. Li Z, Chen W, Xia M, et al. Sleeve lobectomy compared with pneumonectomy for operable centrally located non-small cell lung cancer: a meta-analysis. Transl Lung Cancer Res 2019;8:775-86.

14. Ludwig C, Stoelben E, Olschewski M, et al. Comparison of morbidity, 30-day mortality, and long-term survival after pneumonectomy and sleeve lobectomy for non-small cell lung carcinoma. Ann Thorac Surg 2005;79:968-73.

15. Yildizeli B, Fadel E, Mussot S, et al. Morbidity, mortality, and long-term survival after sleeve lobectomy for

Cite this article as: Li Z, Xia M, Liu C, Wang T, Ren Y, Liu Y. A meta-analysis of minimally invasive surgery versus thoracotomy for centrally located non-small cell lung cancer. J Thorac Dis 2021;13(1):252-261. doi: 10.21037/jtd-20-3273 non-small cell lung cancer. Eur J Cardiothorac Surg 2007;31:95-102.

16. Takeda S, Maeda H, Koma M, et al. Comparison of surgical results after pneumonectomy and sleeve lobectomy for non-small cell lung cancer: trends over time and 20-year institutional experience. Eur J Cardiothorac Surg 2006;29:276-80.

17. Park JS, Yang HC, Kim HK, et al. Sleeve lobectomy as an alternative procedure to pneumonectomy for non-small cell lung cancer. J Thorac Oncol 2010;5:517-20.

18. Merritt RE, Mathisen DJ, Wain JC, et al. Long-term results of sleeve lobectomy in the management of nonsmall cell lung carcinoma and low-grade neoplasms. Ann Thorac Surg 2009;88:1574-81; discussion 1581-2.

19. Mahtabifard A, Fuller CB, McKenna RJ, et al. Videoassisted thoracic surgery sleeve lobectomy: a case series. Ann Thorac Surg 2008;85:S729-32.

20. Lee JG, Cho BC, Bae MK, et al. Thoracoscopic lobectomy is associated with superior compliance with adjuvant chemotherapy in lung cancer. Ann Thorac Surg 2011;91:344-8.

21. Lee PC, Nasar A, Port JL, et al. Long-term survival after lobectomy for non-small cell lung cancer by video-assisted thoracic surgery versus thoracotomy. Ann Thorac Surg 2013;96:951-60; discussion 960-1.

22. Kim SH, Kim HK, Choi YS, et al. Pleural recurrence and long-term survival after thoracotomy and thoracoscopic lobectomy. Ann Thorac Surg 2013;96:1769-75.

23. Okada M, Yamagishi H, Satake S, et al. Survival related to lymph node involvement in lung cancer after sleeve lobectomy compared with pneumonectomy. J Thorac Cardiovasc Surg 2000;119:814-9.

24. Scott WJ, Allen MS, Darling G, et al. Video-assisted thoracic surgery vs open lobectomy for lung cancer: a secondary analysis of data from the American College of Surgeons oncology group Z0030 randomized clinical trial. J Thorac Cardiovasc Surg 2010;139:976-81; discussion 981-3.

(English Language Editors: E. Tan and J. Reynolds) 